Thorax (1969), 24, 10.

\title{
Adenocarcinoma of the lung
}

\author{
J.R. H INDS AND G. C. H I T C H C O K \\ From Green Lane Hospital, Auckland, New Zealand
}

\begin{abstract}
The clinical and histological features of 53 cases of adenocarcinoma of the lung are presented. In more than one-third of the patients the tumour was a solitary nodule, raising the possibility that it might be a metastatic focus. Although histological features may suggest an origin from such sources as the kidney, uterus, ovary or bowel, nearly all such cancers are, in fact, primary bronchial tumours. It is seldom justifiable to submit the patient with a nodular adenocarcinoma in the lung to a search for a possible extrathoracic primary neoplasm.
\end{abstract}

Adenocarcinomas comprise about $10 \%$ of all primary lung cancers. They tend to occur in the more peripheral parts of the lung and are often small and symptomless when first detected radiologically. The location of these tumours encourages surgical resection. The lower male to female ratio of primary adenocarcinomas of the lung compared with the male preponderance for other forms of lung cancer is notable.

The purpose of this paper is to review our experience with this type of cancer, to discuss clinical management, and to indicate the difficulties that may arise when deciding histologically whether the tumours are primary or metastatic.

\section{MATERIAL}

During the five-year period from 1962 to 1966 inclusive, 545 patients with lung cancer were treated at the Thoracic Unit, Green Lane Hospital. The histological classification of these tumours is listed in the Table. As stated later, the alveolar-cell carcinomas are regarded as a subgroup of adenocarcinoma. Initially there was difficulty in deciding whether some of the adenocarcinoma group were primary bronchial tumours or not. With the passage of time it has become evident that these 53 cases were all primary lung tumours. Of this number, 35 were men, giving

\section{T A B L E}

BRONCHIAL CARCINOMA 1962-66 INCLUSIVE

\begin{tabular}{|c|c|c|c|c|c|}
\hline \multicolumn{4}{|c|}{ Histological Type } & \multirow{2}{*}{$\left.\begin{array}{c}\text { No. of Cases } \\
195 \\
200 \\
97 \\
43 \\
10\end{array}\right\} 53$} & \multirow{2}{*}{$\begin{array}{c}\% \text { of Total } \\
35 \cdot 7 \\
36.8 \\
17.8 \\
7.9 \\
1.8\end{array}$} \\
\hline $\begin{array}{l}\text { Squamous cell } \\
\text { Undifferentiated } \\
\text { Large cell } \\
\text { Small cell } \\
\text { Adenocarcinoma } \\
\text { Advootar-cell carci }\end{array}$ & $\begin{array}{l}\cdots \\
\ldots \\
\cdots \\
\text { cinoma }\end{array}$ & $\begin{array}{l}\cdots \\
\cdots \\
\cdots \\
\cdots\end{array}$ & $\begin{array}{l}\cdots \\
\cdots \\
\cdots \\
\cdots\end{array}$ & & \\
\hline Total ... & $\cdots$ & $\cdots$ & $\cdots$ & 545 & $100 \cdot 0$ \\
\hline
\end{tabular}

a male to female ratio of almost $2: 1$. The ages range from 37 to 78 years.

Nineteen $(36 \%)$ of these patients presented with solitary circumscribed opacities of varying sizes an $\vec{\phi}$ underwent exploratory thoracotomy. In each of these cases the possibility of metastatic carcinoma was considered and in 10 of the 19 patients unsolicite histological opinion suggested that the growth was probably metastatic from such sources as the kidne uterus, bowel, ovary or pancreas.

The diagnosis of adenocarcinoma and alveolar-ceß cancer was established in 51 cases by histologicat examination of bronchial biopsy, resected specimens and necropsy material. The remaining two cases in the group were diagnosed by cytological examination of the sputum. Two of the tumours were considered to have arisen in bronchial adenomata (Fig. 1).

Histological criteria followed that described bo Ashley and Davies (1967a), Liebow (1952), Spencer (1962), and Evans (1956). The diagnosis of alveolas cell cancers subgroup was established on the criterif supplied by Watson and Farpour (1966), Liebow (1952), and Anderson (1966).

The histology of the 53 cases of adenocarcinomg has been reviewed by one of us (G.C.H.), and in retrospect those adenocarcinomas formerly though probably to be metastatic have been reclassed as almost certainly of primary bronchial origin.

\section{DEFINITION OF TERMS}

Adenocarcinomas consist predominantly of mucin-secreting or non-mucin-secreting columnå and cuboidal cells arranged as regular or irregula tubular and papillary elements supported by $\overrightarrow{\vec{a}}$ well or poorly developed fibrous stroma. The gland spaces are often imperfectly developed anळ blend inconspicuously with sheet-like prolifer\% tions of neoplastic cells often of pleomorphie character (Figs 1, 5b, and 5c). Some tumours ma exhibit a combination of squamous and tubulag 


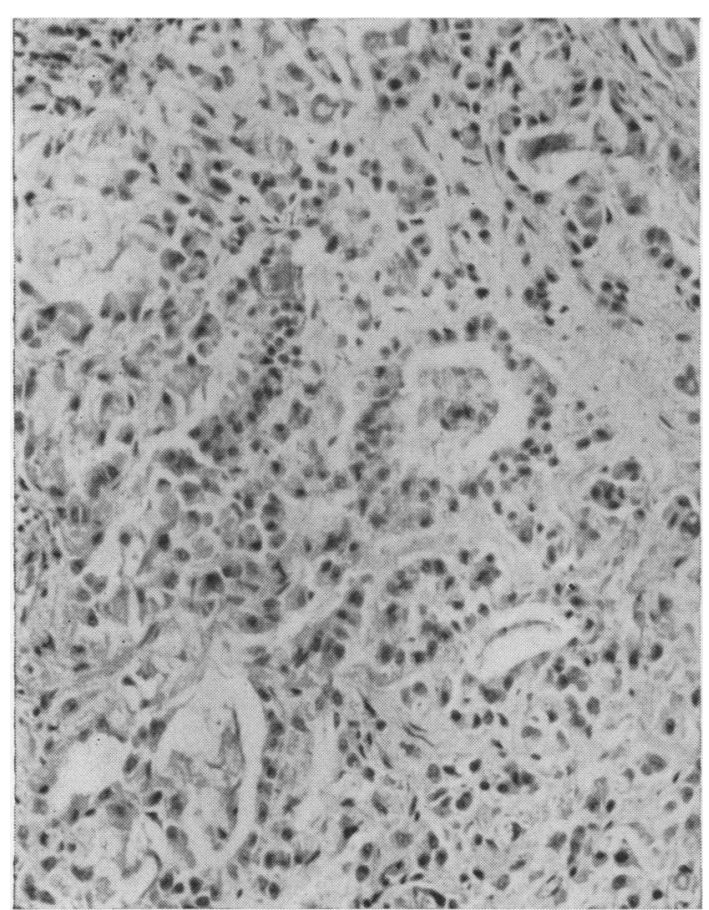

FIG. 1. Case 27. Poorly differentiated adenocarcinoma arising from a previously resected tumour that was originally considered to be a bronchial adenoma. $H$. and $E$., $\times 63$.

features and others may contain, in addition, undifferentiated tissue in which may be seen oat cells, spindle cells, and oval cells. Mucin is produced in varying quantities by the tumour cells and is secreted into the lumina of the tubules and acini. Pools of mucin and 'signet ring' cells may occur.

Alveolar-cell carcinomas are diffuse or focally distributed tumours characterized histologically by cuboidal or columnar cells supported mainly upon the walls of the alveoli. They are usually well-differentiated with a regular pattern and size of acini ; they have a tendency to papillary formation which may be marked. We doubt if the alveolar-cell cancer should be regarded as a separate entity and agree with Wright and Heard (1966) that the distinction between alveolar-cell carcinoma and bronchial adenocarcinoma is 'far from straightforward'. Because of the difficulty in precise histological differentiation between these two cancers, and in view of the variable structure in various parts of these tumours, we prefer to consider alveolar-cell carcinoma as a subgroup of adenocarcinoma.

Synonyms sometimes used for alveolar-cell carcinoma are diffuse epithelial hyperplasia of the lung, bronchiolar carcinoma, and malignant pulmonary adenomatosis. In our opinion, such terms should be avoided as they are not an accurate description of the pathological state and merely serve to confuse.

\section{FINDINGS}

The incidence of adenocarcinoma in our series of lung cancers (Table) is somewhat lower than $13.2 \%$ reported by Patton, McDonald, and Moersch (1951) and 11\% reported by Walter and Pryce (1955), but it is in agreement with Goldman (1965), who found 7\%.

Our incidence of alveolar-cell cancer is a little lower than $2 \cdot 1 \%$ of Watson and Smith (1951) and $2.2 \%$ of Haber (1964). That the male:female ratio is less in patients with adenocarcinoma has been recognized in many series (Spencer, 1962 ; Connelly, Cutler, and Baylis, 1966). In this series the ratio is $1.9: 1.0$.

Ten of the 53 satisfied the histological criteria of the sub-group alveolar-cell cancer. Of these 10, the tumour in five patients was solitary and circumscribed, the nodules varying in size from 2 $\mathrm{cm}$. to $10 \mathrm{~cm}$. in diameter (Figs $2 \mathrm{a}-\mathrm{c}$ ). The other five cases of alveolar-cell tumour showed the diffuse growth which is generally regarded as the characteristic manner in which this type of lung cancer develops. The histological picture does not differentiate the diffuse from the circumscribed tumour.

The smoking habits of the group were recorded. Thirty-two patients were heavy or moderate smokers-over 20 cigarettes a day. Fifteen were non-smokers, who had never smoked, and six patients were trivial or light smokers. It may be remarked here that obviously in this series adenocarcinoma has not spared the non-smoker or light smoker.

\section{NATURAL HISTORY OF ADENOCARCINOMA}

Ashley and Davies (1967a) suggest that when carcinomatous changes occur in bronchial mucosa the resulting histological type of tumour depends on the state of the mucosa. If metaplasia has occurred then squamous cancers will develop. In the more peripheral parts of the bronchial tree exposure to inhaled carcinogens is less, and cancers developing here are more likely to be adenocarcinomas arising from columnar or cuboidal epithelium. These writers also describe the occurrence of mixed adenosquamous cancers (Ashley and Davies, 1967b). Adenocarcinomas, according to Spencer (1962), often arise in association with scar formation in the lung. 


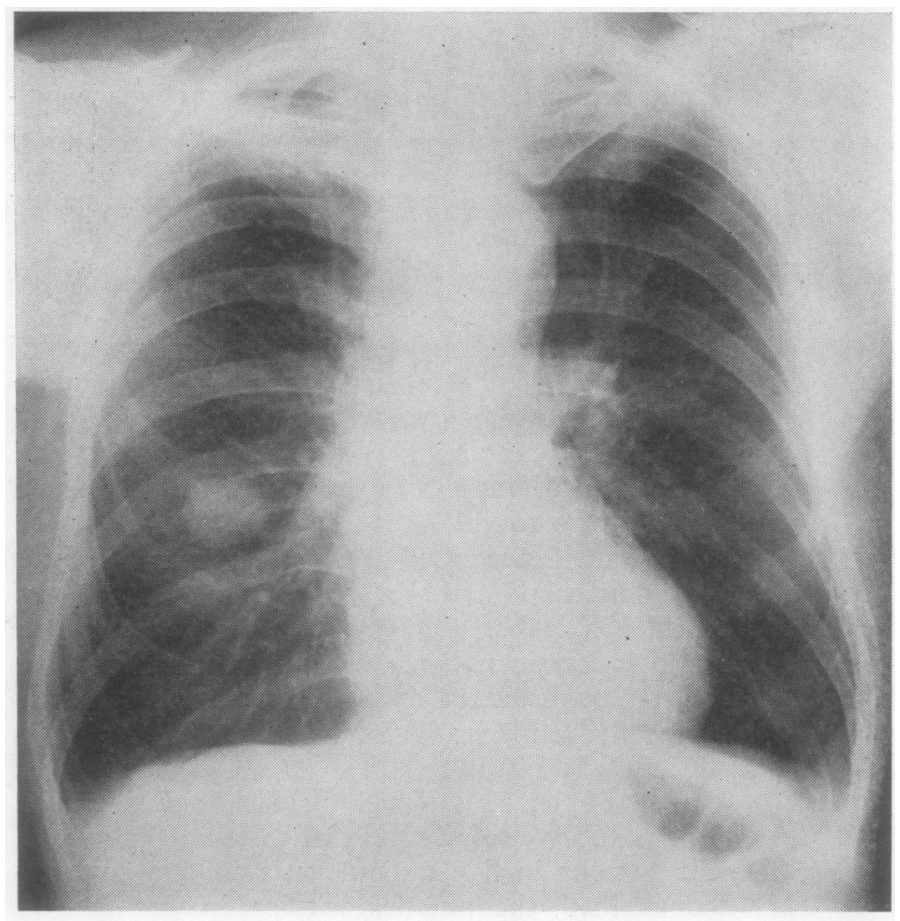

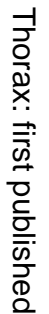

FIG. 2. Case 23, a man aged 57. (a) Ches radiograph shows circumscribed opacity in the right middle zone. Lobectomy. (b) Columnar cells lining air spaces, papillar $\overrightarrow{\mathrm{L}}$ projections, and malignant cells lying free ar ${ }^{5}$ consistent with an alveolar-cell carcinoma $H$. and $E$., $\times 150$. (c) High-power viewx of malignant columnar cells lining air spaces $H$. and $E$., $\times 610$.

(a)

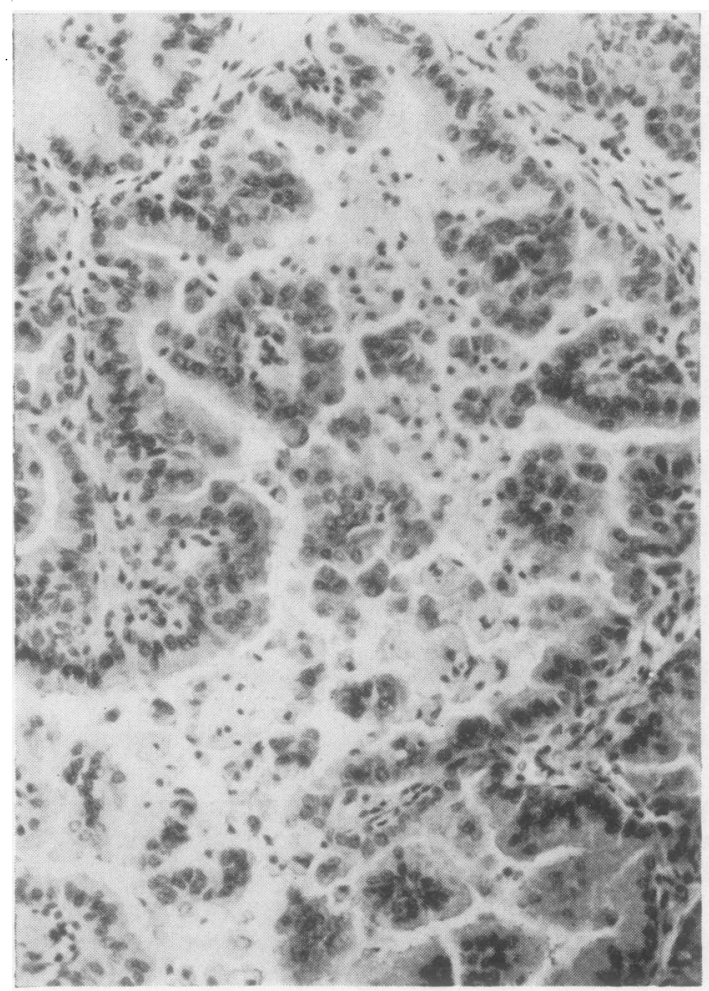

(b)

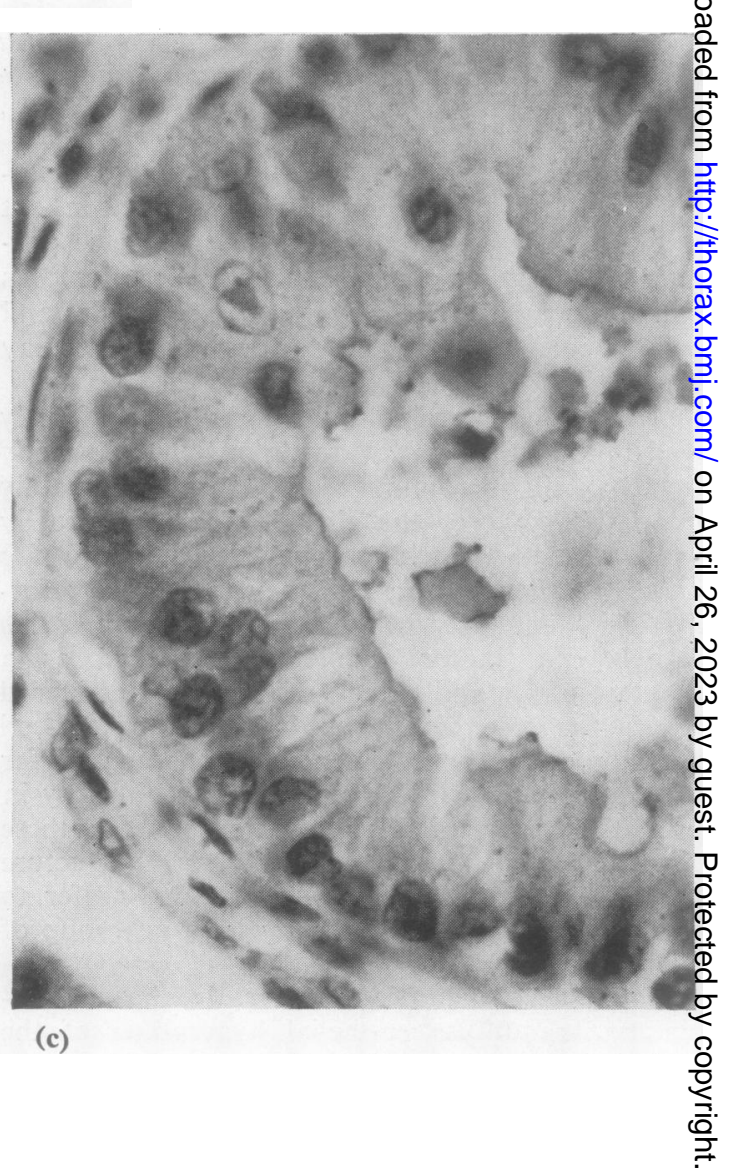


Confusion between adenocarcinoma and alveolar-cell cancer arises because in some instances the growth of an adenocarcinoma may extend along air passages and into air sacs to line the alveoli with malignant columnar or cuboidal epithelium (Evans, 1956). With the alveolar-cell cancers, which behave in a similar way, the alveolar walls are generally well preserved and constitute a supporting framework for the neoplastic cells (Fig. 2b). However, in less well-differentiated growths the alveolar walls are not always intact, and even by the use of elastic tissue stains it may be difficult to define remnants of alveolar septa.

Thompson (1963) also believes that there is no clear distinction between the behaviour of peripheral adenocarcinoma of the lung and the socalled alveolar cell carcinoma. He describes the capacity of the adenocarcinoma to spread locally by implanted seedlings within the bronchial tree, such seedlings on occasions filling the alveoli with malignant cells. The same author states that adenocarcinoma may involve and spread over the pleural surface by multiple seedings to produce a neoplastic carapace. Since the primary tumour may be small and difficult to identify, the diagnosis may well be confused with primary mesothelioma of the pleura.

The lower incidence of adenocarcinoma in men compared with other forms of lung cancer has suggested that these cancers may result from different aetiological factors (Kreyberg, 1952, 1955). Nevertheless the proportion of adenocarcinomas to other types of lung cancers has remained fairly constant in spite of the rapid rise of total lung cancers, a rise generally related to cigarette smoking or exposure to smog (Wynder and Graham, 1950; Thompson, 1963). Statistically, the association of adenocarcinoma with cigarette smoking, although not so convincing as

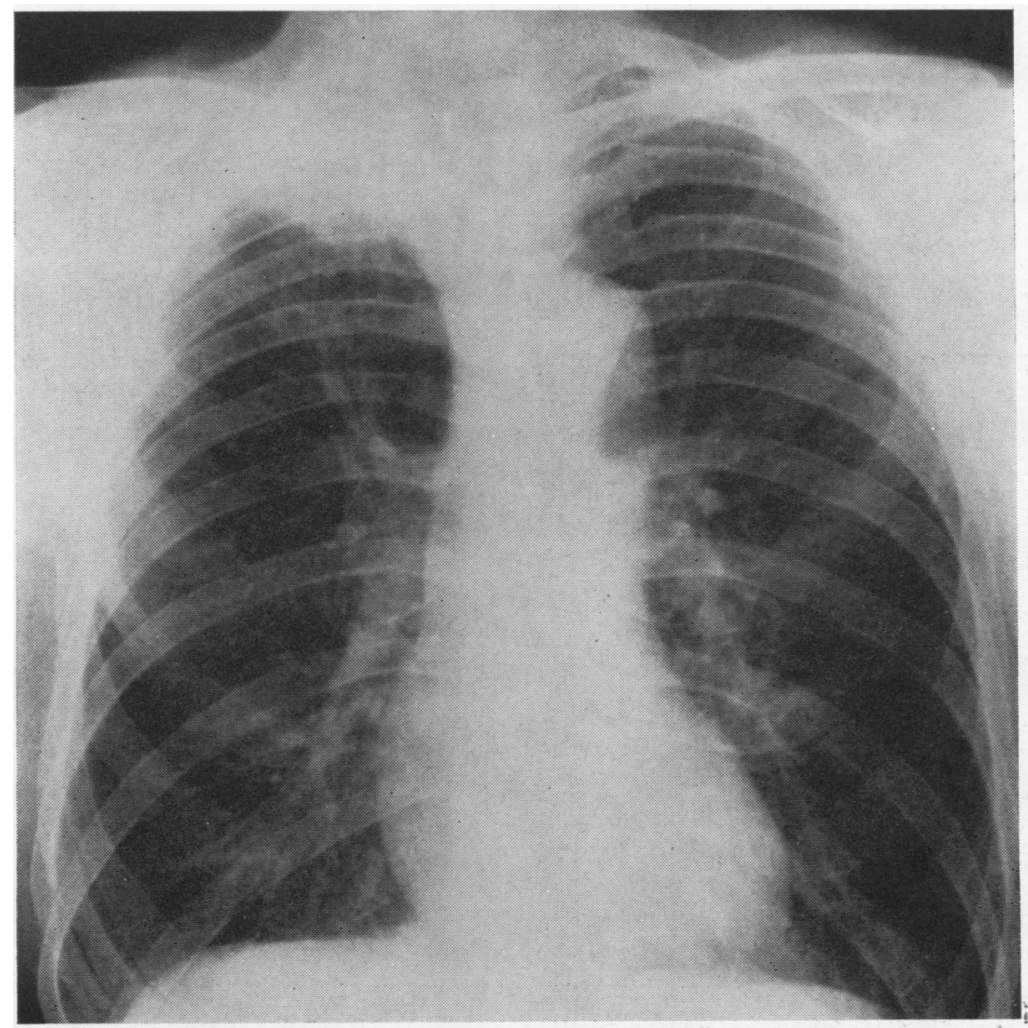

FIG. 3. Case 7, a man aged 58. Chest radiograph shows Pancoast tumour at right apex. A biopsy taken at thoracotomy showed an undifferentiated adenocarcinoma, possibly metastatic from an adrenal or renal tumour. Patient remains' well five years later. 


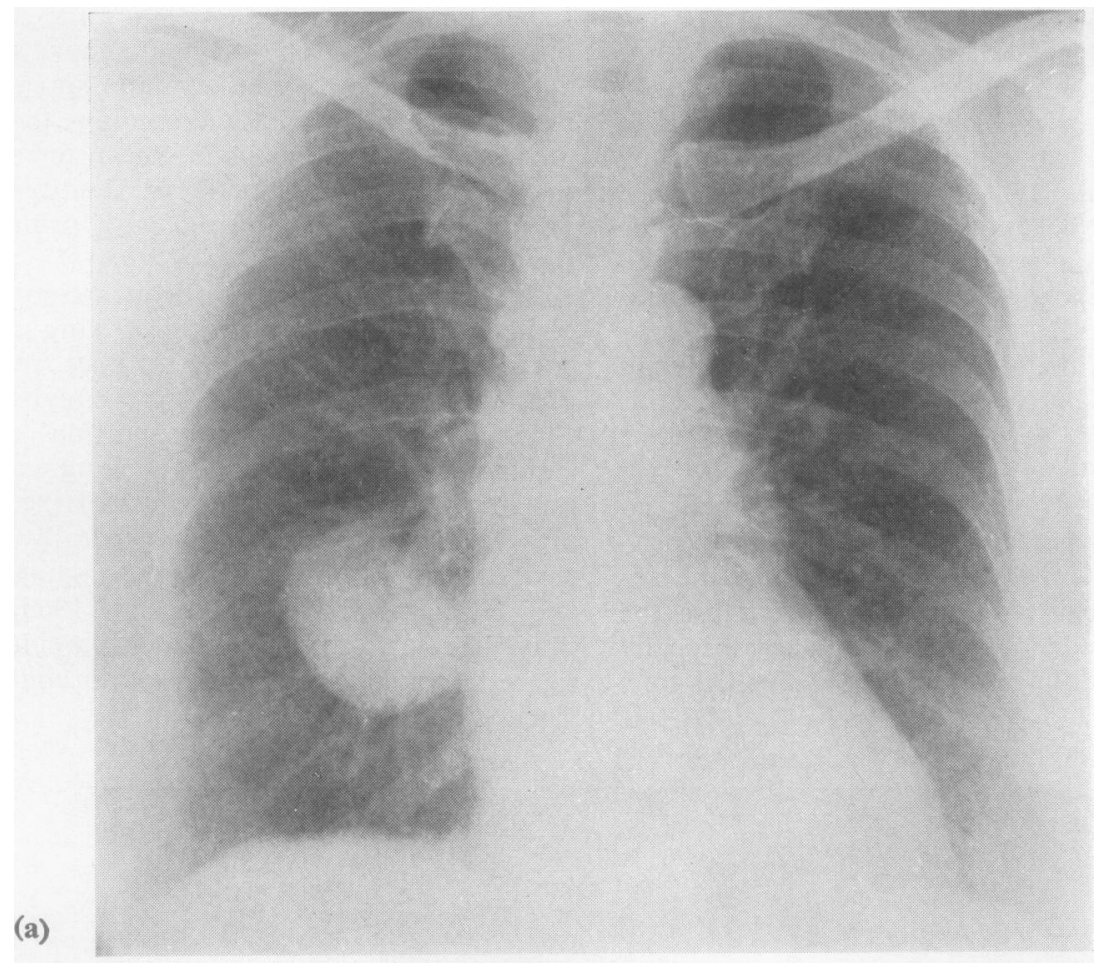

(b)

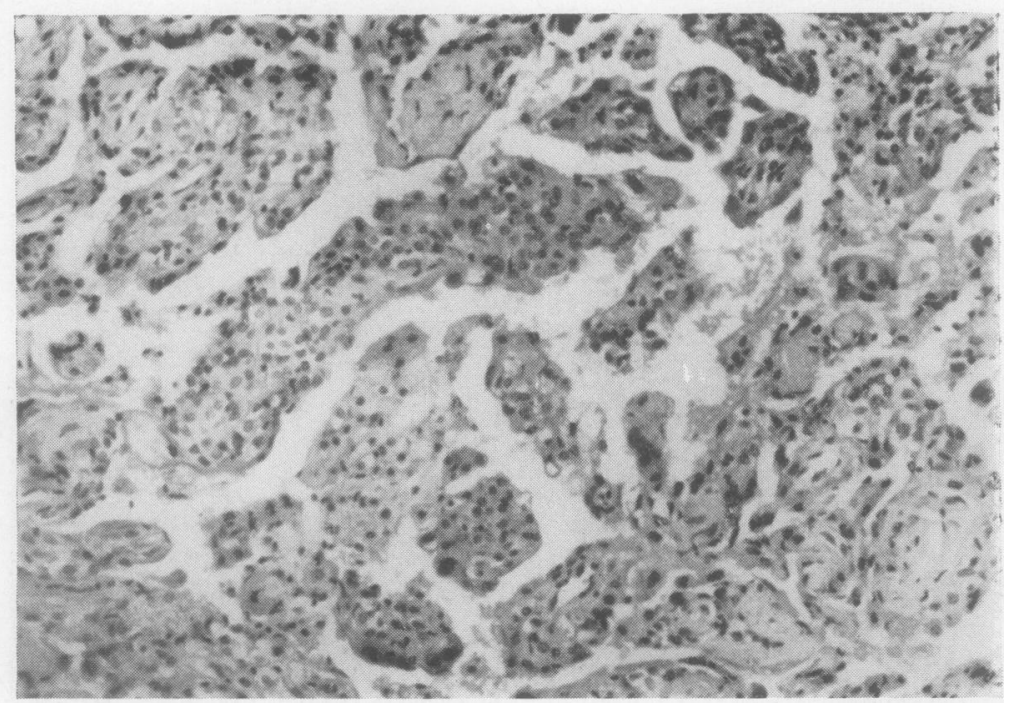

FIG. 4. Case 20, a woman aged 71. (a) Chest radiograph shows the solitary circumscribed tumour. A right lower lobectomy was performed. (b) Poorly differentiated adenocarcinoma confirmed by periodic acid Schiff stain. Initial primary site in kidney or ovary was suggested but no evidence of any extra-pulmonary site seen after $3 \frac{1}{2}$ years. $H$. and $E$., $\times 150$. 


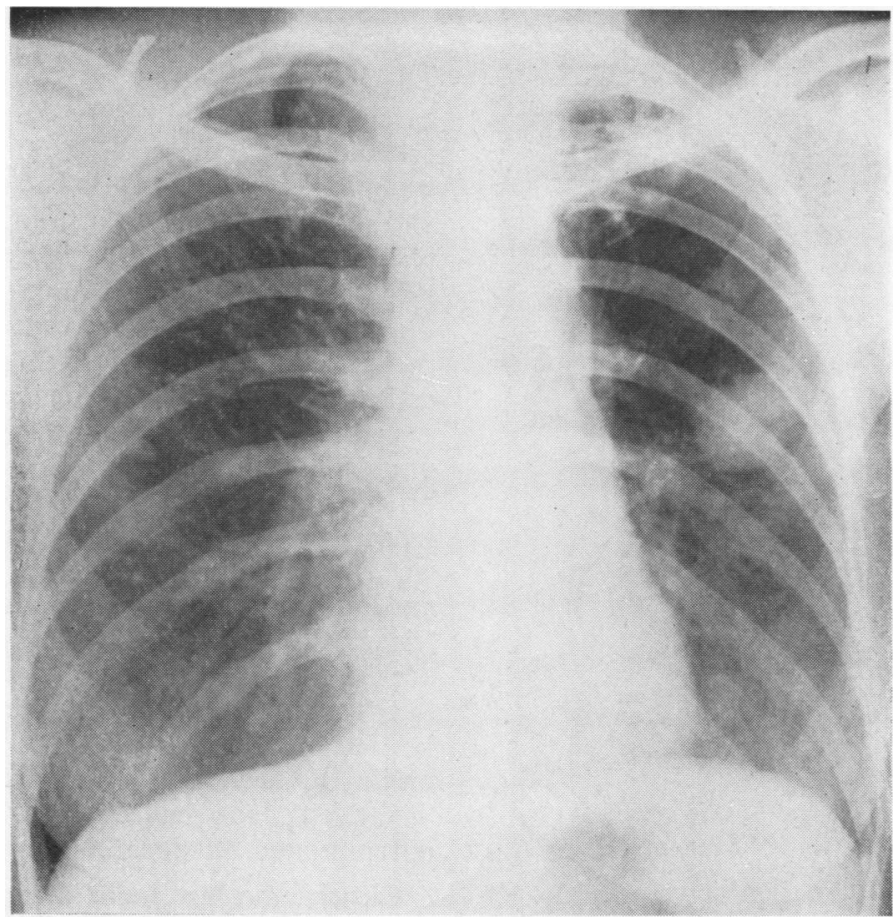

FIG. 5a. Case 40, a woman aged 53. Chest radiograph shows an opacity in the left midzone. This opacity had appeared and grown while she was under treatment for active tuberculosis. A lobectomy was carried out.

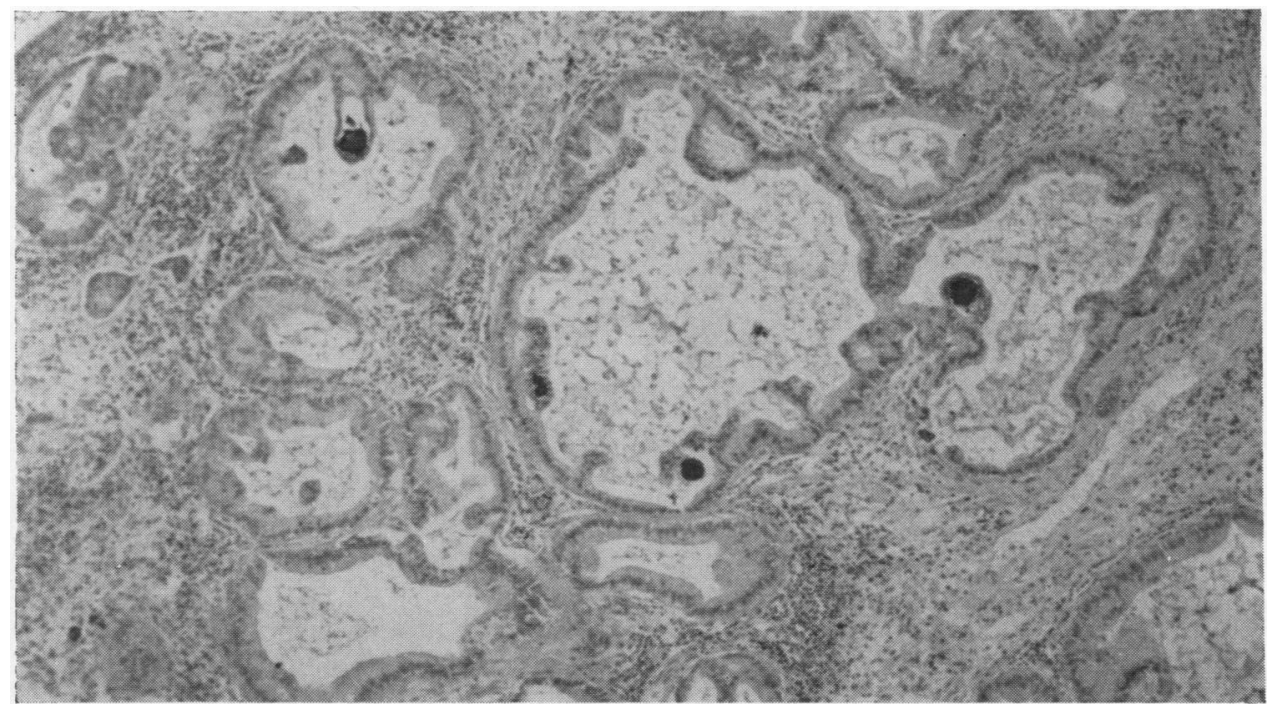

FIG. 5b. Case 40. Shows a well differentiated adenocarcinoma with some areas of calcification. Suggested primary sites for this tumour were colon, ovary or uterus. The patient remains well two years later without further evidence of malignancy. $H$. and $E ., \times 63$. 


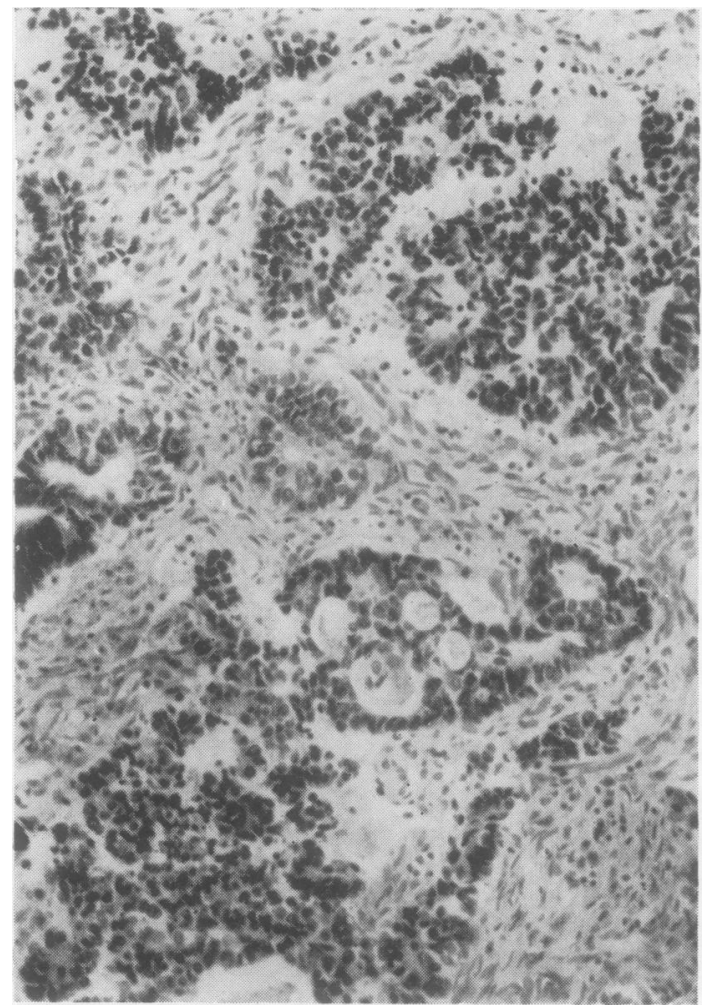

FIG. 5c. Case 41, a man aged 51. P.M. specimen. Histology shows a relatively poorly differentiated adenocarcinoma of lung with ill-defined gland spaces surrounded by fibrous stroma. Compare with Fig. 5b. H. and E., $\times 53$.

with squamous-cell and undifferentiated carcinoma, is becoming increasingly suspect (Doll, Bradford Hill, and Kreyberg, 1957 ; Ashley and Davies, 1967a ; Guillan, Zelman, and Alonso, 1967 ; Wynder and Berg, 1967). Connelly et al. (1966) noted that women with lung cancer have a more favourable prognosis than men, and that adenocarcinoma and alveolar-cell cancer accounted for the larger proportion of cases in women.

Since adenocarcinomas as a group are welldifferentiated tumours they are relatively resistant to both radiotherapy and cytotoxic agents. The rate of growth and spread by distant metastases varies a great deal with the individual patient, not necessarily corresponding with the degree of cellular differentiation. We have been struck by the indolence of the cancer in several patients who have shown little growth of the local lesion and no sign of metastases during a period of five years. An example is shown in Fig. 3 (case 7).

\section{DISCUSSION}

The main concern of this paper is those adeno $\frac{\text { ? }}{0}$ carcinomas (including the subgroup of alveolar $-\overline{\bar{n}}$ cell type) that present as solitary nodules. In theo group of 53 patients, 19 had this type of lesion, and in 10 of these the histological features of the resected specimen suggested a primary source out- $\overrightarrow{0}$ side the lungs. No evidence of any such extra- $-\overrightarrow{\vec{\omega}}$ thoracic source has been evident in the follow-upo period of three to five years. Presented with af solitary circumscribed adenocarcinoma in a re sected lung or lobe the histologist is often, in fact,,+ unable to say whether the growth is of primary $\overrightarrow{.}$ bronchial origin or represents a metastatic deposito from such sources as the kidney, bowel, prostate,, etc. (Figs 4a and $b$ and Figs $5 a$ and $b$ ). Morganand Mackenzie (1964) have drawn attention to theo 'clear-cell' carcinoma of the lung. These tumours? are poorly-differentiated lung adenocarcinomas, but from their histological similarity are likely to be accepted as a metastasis of renal or adrenalo origin. Friedberg (1965) advises that the so-called. 'giant-cell' lung cancer also belongs to the un-O differentiated adenocarcinoma group.

Clearly, the histologist at present cannot go faro in identifying the source of an adenocarcinoma? occurring in the lung. Nor, in our opinion, should $\stackrel{\varrho}{\rightarrow}$ he attempt to do so. The implications following a음 probable diagnosis of metastatic disease are so disturbing that such opinions should not be offered unless they are supported by the strongest evidence.

Admitting the possibility that any resected adenocarcinoma may be a solitary metastasis, the clinician has then to decide what further investigations, if any, are justified or necessary to exclude or identify a possible extrathoracic primary growth. Over the last few years we have adoptedo the policy that, provided on simple clinical assessment there is nothing to suggest an extrathoracico lesion and that the patient is otherwise fit, an exploratory thoracotomy should be carried outo and the nodule should be resected. This has the advantage that an immediate diagnosis of the lung lesion is available and future management can be planned accordingly. If, as usually is the case, the lesion is malignant, one of the remaining problems is whether it is a primary lung neoplasm ores? a metastatic focus. The adenocarcinomas are the cancers in which differentiation between primaryo lung neoplasm and secondaries from extrathoracic요 sources may cause uncertainty.

Although we have not yet found an extra- thoracic cancer that was not already recognized 


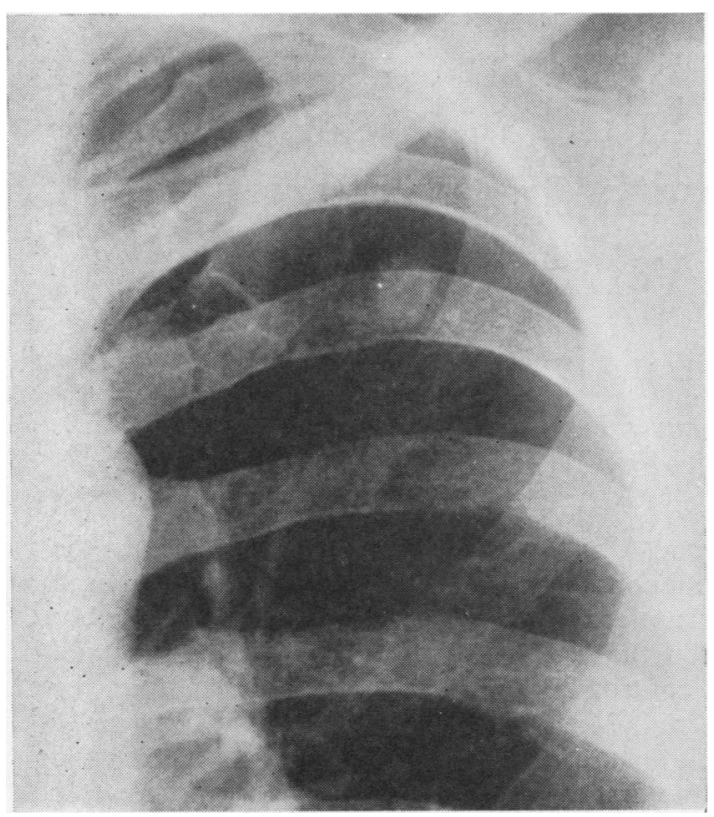

FIG. 6. Case 28, a man aged 42. Chest radiograph shows a small opacity in the first interspace anteriorly. On resection this proved to be an adenocarcinoma. Extensive search for an extrathoracic focus was negative. The patient remains well; although extremely apprehensive, three years after resection.

prior to lung surgery, we have learned that efforts to exclude such a possibility can be complicated, time-consuming, expensive, generally fruitless, and, worst of all, disturbing and upsetting to the patient who has to be made aware of the reasons for further investigations. The defence put forward for trying to identify a hitherto occult primary focus is that an outside chance may exist that the primary lesion is resectable and that the metastatic deposit, already resected, was solitary. In the light of our experience, we believe the patient can justifiably be left undisturbed after the lung resection for an adenocarcinoma. We have followed this deliberately conservative management for the last few years and have not regretted the policy. It is certain that many patients would be grateful if they could appreciate the physical and mental trauma they have been spared in the search for non-existent extrathoracic primary cancers (Fig. 6, case 28).

A solitary nodular adenocarcinoma in the lung, whether large or small, poorly differentiated or well differentiated, is nearly always of primary bronchial origin.

\section{REFERENCES}

Anderson, W. A. D. (1966). Contributions of pathology to problems of human and experimental lung cancer. Amer.J. clin. Path., 46, 3.

Ashley, D. J. B., and Davies, H. D. (1967a). Cancer of the lung. Histology and biological behavior. Cancer, 20, 165. (1967b). Mixed glandular and squamous-cell carcinoma of the bronchus. Thorax, 22, 431.

Connelly, R. R., Cutler, S. J., and Baylis, P. (1966). End results in cancer of the lungs: comparison of male and female patients. J. nat. Cancer Inst., 36, 277.

Doll, R., Bradford Hill, A., and Kreyberg, L. (1957). The significance of cell type in relation to the aetiology of lung cancer. Brit.J. Cancer, 11, 43.

Evans, R. W. (1956). Histological Appearances of Tumours. Livingstone, London.

Friedberg, E. C. (1965). Giant-cell carcinoma of the lung. A dedifferentiated adenocarcinoma. Cancer (Philad.), 18, 259.

Guillan, R. A., Zelman, S., and Alonso, R. A. (1967). Adenocarcinoma of the lungs. An analysis of 24 cases in men. Amer. $J$. clin. Path., 47, 580.

Goldman, K. P. (1965). Histology of lung cancer in relation to prognosis. Thorax, 20, 298.

Haber, R. W. (1964). A review of 995 cases of primary carcinoma of the lung. Med. J. Aust., 1, 551.

Kreyberg, L. (1952). One hundred consecutive primary epithelial lung tum ours. Brit. J. Cancer, 6, 112.

(1955). Lung cancer and tobacco smoking in Norway. Ibid., 9, 495.

Liebow, A. A. (1 952). Atlas of Tumor Pathology. Section V, Fascicle 17: Tumors of the Lower Respiratory Tract. Armed Forces Institute of Pathology, Washington, D.C.

Morgan, A. D., and Mackenzie, D. H. (1964). Clear-cell carcinoma of the lung. J. Path. Bact., 87, 25.

Patton, M. M., McDonald, J. R., and Moersch, H. J. (1951). Bronchogenic adenocarcinoma. J. thorac. Surg., $22,83$.

Spencer, H. (1962). Pathclcgy of the Lung. Pergamon Press, Oxford. Thompson, V. C. (1963). In Chest Diseases, Vol. 2, p. 567, ed. Perry K. M. A., and Holmes Sellors, T. Butterworths, London.

Walter, J. B., and Pryce, D. M. (1955). The histology of lung cancer. Thorax, 10, 107.

Watson, W. L., and Farpour, A. (1966). Terminal bronchiolar or 'alveolar cell' cancer of the lung. Cancer (Philad.), 19, 776.

- and Smith, R. R. (1951). Terminal bronchiolar or 'alveolar cell' cancer of the lung. J. Amer. med. Ass., 147, 7.

Wright, G. Payling, and Heard, B. E. (1966). Systemic Pathology, Vol. 1. ed. Wright, G. Payling, and Symmers, W. St. C., p. 412. Longmans, London.

Wynder, E. L., and Berg, J. W. (1967). Cancer of the lung among nonsmokers. Special reference to histologic patterns. Cancer (Philad.), 20, 1161.

and Graham, E. A. (1950). Tobacco smoking as a possible etiologic factor in bronchiogenic carcinoma. J. Amer. med. Ass. $143,329$. 